\title{
Doping Lanthanide Nanocrystals With Non-lanthanide Ions to Simultaneously Enhance Up- and Down-Conversion Luminescence
}

\begin{abstract}
Yingying $\mathrm{Li}^{1,2}$, Chunyan Liu ${ }^{1 *}$, Peisen Zhang ${ }^{1,2}$, Jiayi Huang ${ }^{1,2}$, Haoran Ning ${ }^{1,2}$, Peng Xiao ${ }^{1,2}$, Yi Hou ${ }^{1}$, Lihong Jing ${ }^{1 *}$ and Mingyuan Gao ${ }^{1,2,3 *}$

${ }^{1}$ Key Laboratory of Colloid, Interface and Chemical Thermodynamics, Institute of Chemistry, Chinese Academy of Sciences, Beijing, China, ${ }^{2}$ School of Chemistry and Chemical Engineering, University of Chinese Academy of Sciences, Beijing, China, ${ }^{3}$ Center for Molecular Imaging and Nuclear Medicine, School for Radiological and Interdisciplinary Sciences (RAD-X), Collaborative Innovation Center of Radiation Medicine of Jiangsu Higher Education Institutions, and State Key Laboratory of Radiation Medicine and Protection, Soochow University, Suzhou, China
\end{abstract}

The rare-earth nanocrystals containing $\mathrm{Er}^{3+}$ emitters offer very promising tools for imaging applications, as they can not only exhibit up-conversion luminescence but also down-conversion luminescence in the second near-infrared window (NIR II). Doping non-lanthanide cations into host matrix was demonstrated to be an effective measure for improving the luminescence efficiency of $\mathrm{Er}^{3+}$ ions, while still awaiting in-depth investigations on the effects of dopants especially those with high valence states on the optical properties of lanthanide nanocrystals. To address this issue, tetravalent $\mathrm{Zr}^{4+}$ doped hexagonal $\mathrm{NaGdF}_{4}: \mathrm{Yb}, \mathrm{Er}$ nanocrystals were prepared, and the enhancement effects of the $\mathrm{Zr}^{4+}$ doping level on both up-conversion luminescence in the visible window and down-conversion luminescence in NIR II window were investigated, with steady-state and transient luminescence spectroscopies. The key role of the local crystal field distortions around $\mathrm{Er}^{3+}$ emitters was elucidated in combination with the results based on both of $\mathrm{Zr}^{4+}$ and its lower valence counterparts, e.g., $\mathrm{Sc}^{3+}, \mathrm{Mg}^{2+}, \mathrm{Mn}^{2+}$. Univalent ions such as $\mathrm{Li}^{+}$was utilized to substitute $\mathrm{Na}^{+}$ion rather than $\mathrm{Gd}^{3+}$, and the synergistic effects of $\mathrm{Zr}^{4+}$ and $\mathrm{Li}^{+}$ions by co-doping them into $\mathrm{NaGdF}_{4}: \mathrm{Yb}, \mathrm{Er}$ nanocrystals were investigated toward optimal enhancement. Upon optimization, the up-conversion emission of co-doped $\mathrm{NaGdF}_{4}: \mathrm{Yb}$,Er nanocrystals was enhanced by more than one order of magnitude compared with undoped nanocrystals. The current studies thus demonstrate that the local crystal field surrounding emitters is an effective parameter for manipulating the luminescence of lanthanide emitters.

Keywords: non-lanthanide doping, up- and down-conversion luminescence, crystal field, valence state effects, rare-earth nanocrystals, lanthanide emitters

\section{INTRODUCTION}

Rare-earth (RE) nanocrystals are promising light-emitting materials as they are able to convert near infrared (NIR) photons into ultraviolet, visible, and NIR lights through either an up-conversion path or a down-conversion path (Chen et al., 2013; Dong et al., 2015). Compared with conventional down-conversion luminescent materials such as organic dyes and semiconductor quantum dots 
(Antaris et al., 2016; Chen B.K. et al., 2017; Stroyuk et al., 2018; Lu et al., 2020), rare-earth nanocrystals offer remarkable optical advantages, such as narrow "atomic-line" emission from the internal f-f transitions of lanthanide ions, large stokes or antistokes shifts, long luminescence lifetime, and high photochemical stability, and thus are potentially useful for diverse imaging applications (Zhou et al., 2012; Liu et al., 2014; Fan et al., 2018; Ai et al., 2019). Especially, emitting lanthanide $\mathrm{Er}^{3+}$ ions based rareearth nanocrystals have aroused intense interests because $\mathrm{Er}^{3+}$ ions present a longer down-conversion emission wavelength at $1,525 \mathrm{~nm}$ in the second NIR window (NIR II, 1,000-1,700 nm), which enables a virtual zero auto-fluorescence interference of tissues in bio-imaging, apart from the up-conversion emission at $541 \mathrm{~nm}$ and $656 \mathrm{~nm}$ in the visible and NIR I region (NIR I, 650-950 nm), respectively (Shen et al., 2013; Xu et al., 2019). However, due to the low absorption cross-section $\left(\sim 10^{-20} \mathrm{~cm}^{2}\right)$ of lanthanide ions caused by the parity-forbidden transition of 4 f electrons ( $\mathrm{Tu}$ et al., 2015), and non-radiative relaxation between multi-energy levels, their up- and down-conversion luminescence efficiencies are generally low, which obviously hinders their applications. In principle, $\mathrm{Yb}^{3+}$ ions are suitable for sensitizing the up-conversion luminescence of $\mathrm{Er}^{3+}$ ions, benefiting from the large absorption cross-section of $\mathrm{Yb}^{3+}$ ions. Increasing the concentration of sensitizer or emitter have been adopted to improve the luminescence upon $980 \mathrm{~nm}$ excitation (Chen Q.S. et al., 2017; Ma et al., 2017), but overincreasing the concentration of $\mathrm{Yb}^{3+}$ is unfavorable owing to the participation of $\mathrm{Yb}^{3+}$ ions on the particle surface in dissipating the absorbed energy (Johnson et al., 2017).

Apart from sensitizing ion doping, significant progresses have also been made for improving the up-conversion luminescence of $\mathrm{Er}^{3+}$ ions in rare-earth nanocrystals through surface passivation by forming core-shell structures (Yi and Chow, 2007; Fan et al., 2019), surface plasmon coupling by conjugating to noble metal particles (Sun et al., 2014; Clarke et al., 2018), and host-lattice manipulation by non-lanthanide ( $\mathrm{Ln}$ ) ions doping (Dong et al., 2013). The epitaxial growth of a shell on preformed emitting core, e.g., growing $\mathrm{NaGdF}_{4}$ shell on $\mathrm{NaGdF}_{4}$ : $\mathrm{Yb}$,Er core (Vetrone et al., 2009; Li et al., 2013), can suppress the energy transfer from the emitting core to surrounding environment, thus favorable for boosting the luminescence efficiency, apart from giving rise to stable and controllable core/shell structures (Wang et al., 2010). However, this approach will require at least two successive steps of preparations (He et al., 2017). Modifying rare-earth nanocrystals with plasmonic noble metal can efficiently improve the luminescence by changing the surface electronic field, but also leads to relatively large and less stable structures that may be disassociated under certain conditions. Different from these two approaches, doping non-Ln ions to enhance the luminescence through modulating the local chemical environment of the emitting centers doesn't necessarily increase the particle size apart from forming more stable structures (Huang et al., 2019). Because of the interplay between the $4 \mathrm{f}$ electrons of $\mathrm{Er}^{3+}$ and the crystal field of the host doped with non-Ln ions, the probability of radiative transitions within $\mathrm{Er}^{3+}$ can hopefully be enhanced by relaxing the selection rules (Fischer et al., 2019). For example, metal ions such as $\mathrm{Li}^{+}, \mathrm{Ca}^{2+}, \mathrm{Mn}^{2+}$, and $\mathrm{Fe}^{3+}$, were adopted as non-Ln dopants to enhance the up-conversion luminescence (Cheng et al., 2012; Zeng et al., 2014; Tang et al., 2020b; Verma et al., 2020). Doping of $\mathrm{Li}^{+}$ions was demonstrated to increase the up-conversion luminescence of $\mathrm{Y}_{2} \mathrm{O}_{3}: \mathrm{Yb}, \mathrm{Er}$ nanocrystals by factors of 8-25 (Chen et al., 2008). Doping of alkaline-earth ions such as $\mathrm{Ca}^{2+}$ was also found to improve the uniformity of the resulting $\mathrm{NaGdF}_{4}: \mathrm{Yb}, \mathrm{Er}$ nanocrystals, apart from enhancing the up-conversion luminescence (Lei et al., 2013). Doping $\mathrm{Fe}^{3+}$ into a $\mathrm{NaYF}_{4}: \mathrm{Yb}$,Er nanocrystals selectively enhanced the red up-conversion luminescence of $\mathrm{Er}^{3+}$ ions by 7 times (Tang et al., 2015). Nevertheless, doping of $3 d$ transition metal ions such as $\mathrm{Mn}^{2+}$ or $\mathrm{Fe}^{3+}$ into host will introduce new energy levels associated with partially filled $3 d$ orbitals of the dopant, particularly when the doping level is high enough. In consequence, additional electronic transition pathways may be created to alter the up-conversion emission position or decrease the up-conversion luminescence intensity. However, the effect of dopant ions on the down-conversion luminescence of $\mathrm{Er}^{3+}$ remains rarely addressed. Besides, the dopants are mainly chosen from low valence state ions. Therefore, it is fundamentally interesting to study the high valence dopants particularly those free of $\mathrm{d}$-d transitions for improving the up- and down-conversion luminescence of $\mathrm{Er}^{3+}$ based RE luminescent nanocrystals. But there is a clear lack of a systematic study in this respect.

Following our previous investigations on the synthesis and optical properties of RE nanocrystals (Liu et al., 2013; Huang et al., 2015; Li et al., 2019), herein we report hexagonal $\mathrm{NaGdF}_{4}$ :Yb,Er nanocrystals doped with tetravalent $\mathrm{Zr}^{4+}$ ions that possess $\mathrm{d}^{0}$ configuration, and studied the $\mathrm{Zr}^{4+}$ doping level-dependent luminescence properties of $\mathrm{Er}^{3+}$ through both steady-state and transient luminescence spectroscopies. The resulting $\mathrm{Zr}^{4+}$-doped $\mathrm{NaGdF}_{4}$ :Yb,Er nanocrystals exhibited enhanced emissions for both up-conversion luminescence and down-conversion emission peaking at $1,525 \mathrm{~nm}$. The role of $\mathrm{Zr}^{4+}$ dopants in altering the local crystal field of the emitters was discussed in combination with Judd-Ofelt theory. To disclose the underlying mechanisms, the effects of the valence state of the dopant ions on the luminescence properties were investigated by doping $\mathrm{NaGdF}_{4}: \mathrm{Yb}, \mathrm{Er}$ nanocrystals with $\mathrm{Sc}^{3+}, \mathrm{Mg}^{2+}, \mathrm{Mn}^{2+}$, respectively, for comparing with the $\mathrm{Zr}^{4+}$-doped counterpart. Different from above dopants, univalent ion such as $\mathrm{Li}^{+}$was doped into $\mathrm{NaGdF}_{4}: \mathrm{Yb}, \mathrm{Er}$ nanocrystals by substituting $\mathrm{Na}^{+}$rather than $\mathrm{Gd}^{3+}$, and the synergistic effects of $\mathrm{Zr}^{4+}$ and $\mathrm{Li}^{+}$ions by co-doping them into $\mathrm{NaGdF}_{4}: \mathrm{Yb}$,Er nanocrystals were investigated toward optimal enhancement.

\section{RESULTS AND DISCUSSION \\ Synthesis of $\mathrm{Zr}^{4+}$-Doped $\mathrm{NaGdF}_{4}: \mathrm{Yb}, \mathrm{Er}$ Nanocrystals}

$\mathrm{Zr}^{4+}$-doped $\mathrm{NaGdF}_{4}: \mathrm{Yb}, \mathrm{Er}$ nanocrystals were synthesized via a high temperature approach using oleic acid (OA) as the particle surface capping ligand. As displayed in Figure 1a, the asprepared $\mathrm{NaGdF}_{4}: \mathrm{Yb}$,Er nanocrystals are quasi-spherical. After 


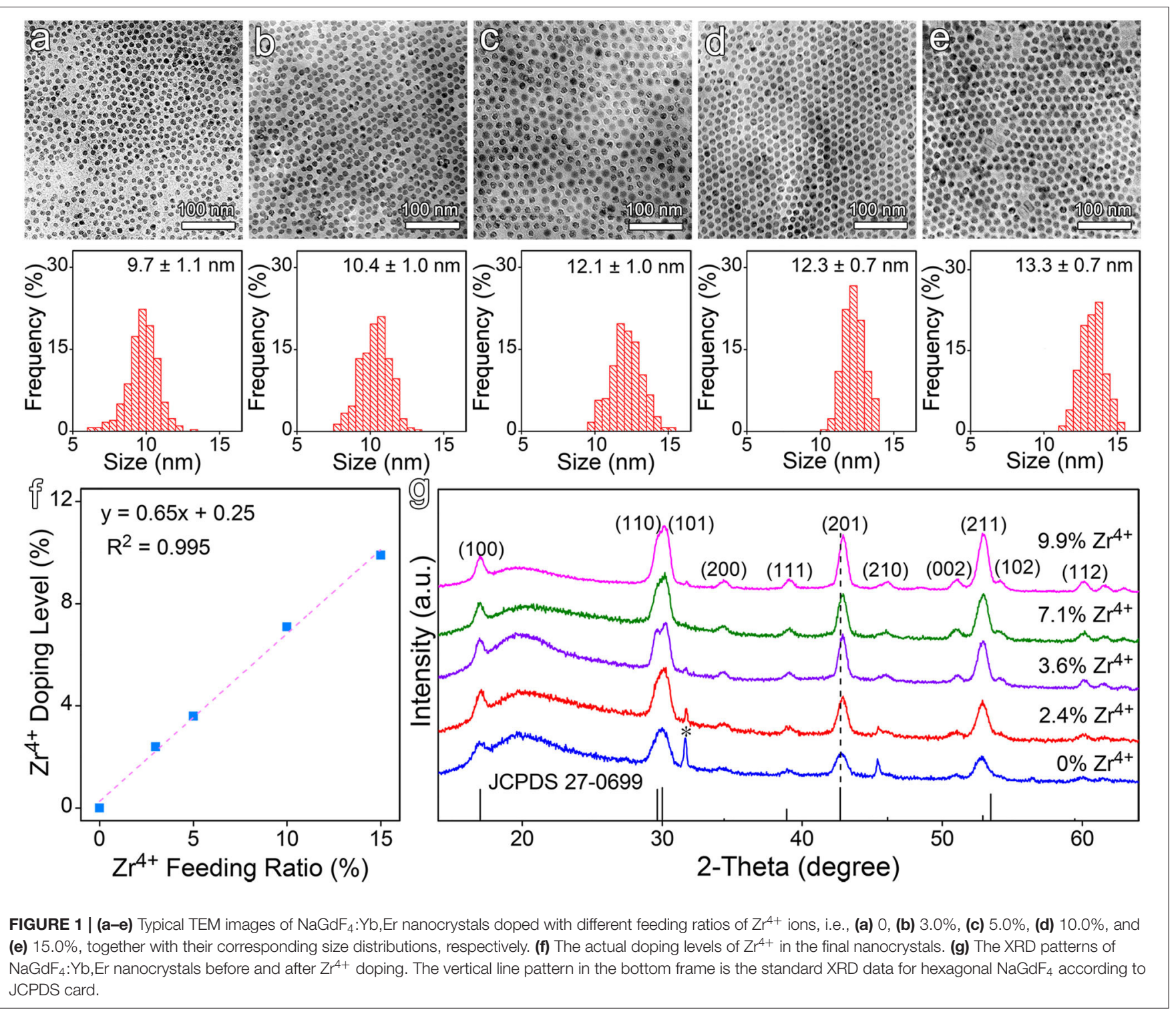

doped with $\mathrm{Zr}^{4+}$ ions, as shown in Figures $\mathbf{1 b}$-e, the nanocrystals slightly increase in particle size from $9.7 \pm 1.1 \mathrm{~nm}$ to $13.3 \pm$ $0.7 \mathrm{~nm}$, depending on the initial feeding molar ratio of $\mathrm{Zr}^{4+}$ to the total cations. Meanwhile, the relative standard deviation (RSD) of the particle size was reduced from 11.3 to $5.3 \%$. Further ICP-AES results demonstrated that the $\mathrm{Zr}^{4+}$ ions were successfully doped into the $\mathrm{NaGdF}_{4}: \mathrm{Yb}, \mathrm{Er}$ nanocrystals and the actual doping level of $\mathrm{Zr}^{4+}$ in the final particles goes linearly from 2.4 to $9.9 \%$ against the initial feeding molar ratio of $\mathrm{Zr}^{4+}$ from 3.0 to $15.0 \%$, as shown in Figure 1f.

It's worth noting that the size of the doped nanocrystals is positively correlated with the doping level of $\mathrm{Zr}^{4+}$ ions. In the current reaction system, $\mathrm{OA}$ acts as a coordinating solvent. It forms metal oleate with the metal precursors prior to the formation of the target nanocrystals. In this context, OA is expected to show higher binding affinity to $\mathrm{Zr}^{4+}$ ion than to $\mathrm{Gd}^{3+}$ ion due to the smaller radius and higher valence of $\mathrm{Zr}^{4+}$.
The energy barrier for decomposing $\mathrm{Zr}$ oleate is expected to be higher than that for Gd oleate, which can find supports from the difference in the bond dissociation energies, i.e., 766.1 $\mathrm{kJ} / \mathrm{mol}$ for $\mathrm{Zr}-\mathrm{O}$ and $715 \mathrm{~kJ} / \mathrm{mol}$ for $\mathrm{Gd}-\mathrm{O}$. Consequently, the supersaturation level as well as the number of nuclei is decreased in the reaction system as a function of $\mathrm{Zr}^{4+}$ precursor concentration, which explains the dependency of particle size on the $\mathrm{Zr}^{4+}$ feeding ratio (Buonsanti and Milliron, 2013).

The crystal structure of all aforementioned samples was analyzed by powder XRD. As shown in Figure 1g, both undoped and $\mathrm{Zr}^{4+}$-doped $\mathrm{NaGdF}_{4}: \mathrm{Yb}$,Er nanocrystals display a hexagonal phase structure. Although the doped samples exhibit similar diffraction patterns, the diffraction peak of (201) crystal plane gradually shifts to higher angles along with the increase of $\mathrm{Zr}^{4+}$ dopant concentration, indicating an effective incorporation of $\mathrm{Zr}^{4+}$ ions into the host lattice. It can then be deduced that the $\mathrm{Zr}^{4+}$ ions substitute $\mathrm{Gd}^{3+}$ ions rather than staying at the 

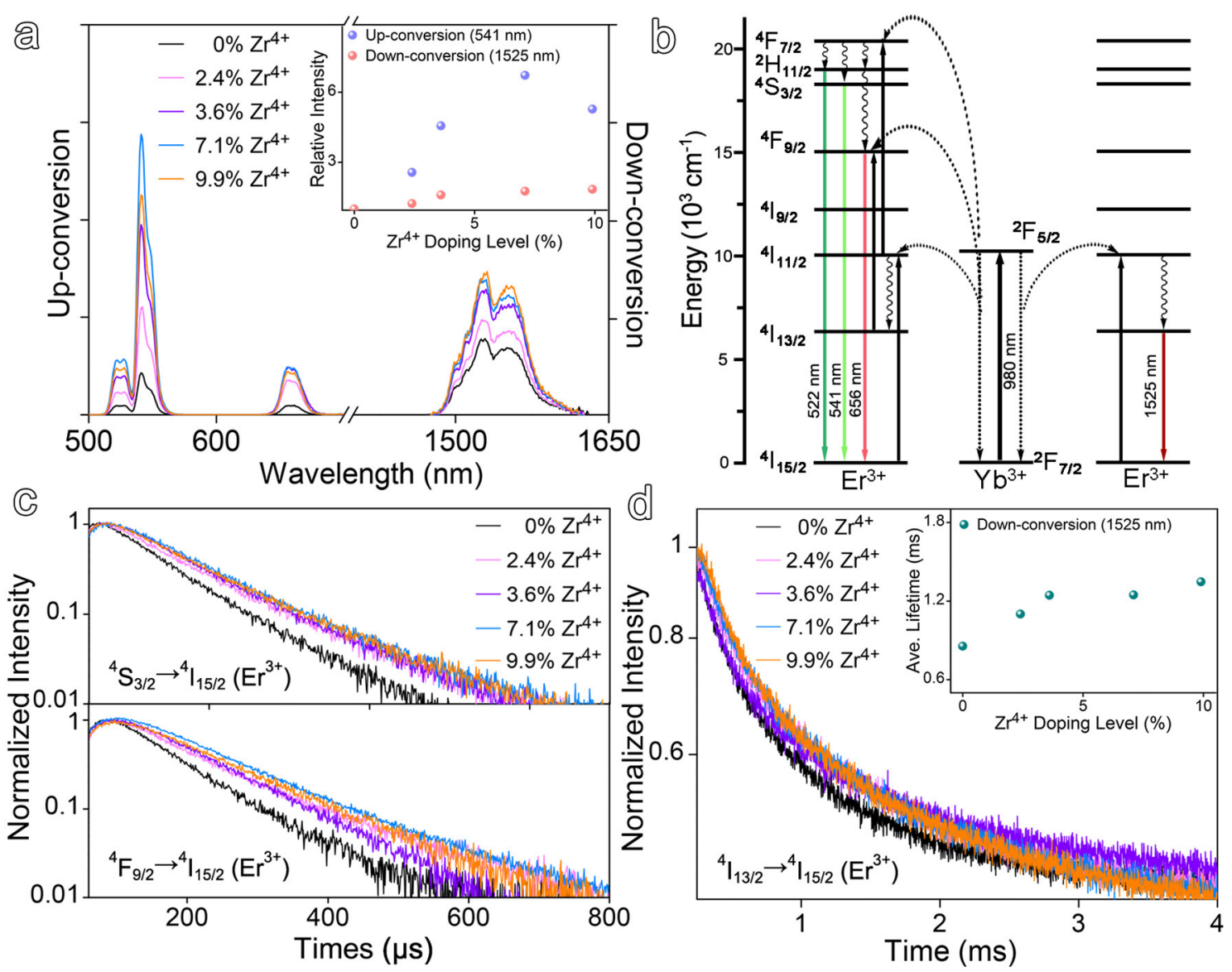

FIGURE 2 | (a) Up- and down-conversion luminescence spectra of $Z r^{4+}$-doped $\mathrm{NaGdF}_{4}$ :Yb,Er nanocrystals at varying doping ratios of $Z r^{4+}$ ions under 980 nm laser excitation and the up- and down-conversion emission intensities as a function of $Z r^{4+}$ doping level, respectively. (b) Simplified energy level diagrams depicting the

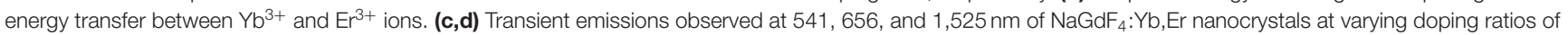
$\mathrm{Zr}^{4+}$ ions.

interstitial sites, because substituting the $\mathrm{Gd}^{3+}$ cations with smaller $\mathrm{Zr}^{4+}$ ions will cause the host lattice to shrink according to Bragg's Law ( $2 \mathrm{~d} \sin \theta=\mathrm{n} \lambda$ ), while occupying the interstitial sites will cause the host lattice to expand. According to the ICPAES results given in Table $\mathbf{S 1}$ in supplementary material the concentration of $\mathrm{Gd}^{3+}$ in the nanocrystals was decreased with the increase of $\mathrm{Zr}^{4+}$ doping level, which strongly supports the above structural analysis. While the gradually narrowed full width at half maximum (FWHM) of the main diffraction peaks, as shown in Figure S1, suggested that $\mathrm{Zr}^{4+}$ doping didn't decrease the crystalline degree, which is the most important prerequisite for improving the luminescence properties of the doped nanocrystals through the manipulation of the crystal field around the emitting ions.

\section{Up- and Down-Conversion Luminescence of $\mathrm{Zr}^{4+}$-Doped $\mathrm{NaGdF}_{4}$ :Yb,Er Nanocrystals}

As demonstrated by the results given in Figure 1 that the particle size and size distribution are dependent on the doping level of $\mathrm{Zr}^{4+}$, it is interesting to learn the dependency of optical properties of the resulting nanocrystals on the doping level of
$\mathrm{Zr}^{4+}$ as well. In the absence of $\mathrm{Zr}^{4+}$ dopant, the $\mathrm{NaGdF}_{4}: \mathrm{Yb}, \mathrm{Er}$ nanocrystals exhibit multiple emissions upon $980 \mathrm{~nm}$ excitation e.g., up-conversion emissions peaking at 541 and $656 \mathrm{~nm}$, down-conversion emission peaking at $1,525 \mathrm{~nm}$, respectively, as shown in Figure 2a. In the presence of $\mathrm{Zr}^{4+}$ dopants, the luminescence intensity of the up-conversion emission at $541 \mathrm{~nm}$ is dramatically increased against the $\mathrm{Zr}^{4+}$ content and gets enhanced by a factor of 6.7 when the $\mathrm{Zr}^{4+}$ content reaches $7.1 \%$, and then becomes decreased upon further increase of the $\mathrm{Zr}^{4+}$ content. Meanwhile, the luminescence intensity of the down-conversion emission presents a similar tendency and gets enhanced by a factor of 1.8 when the $\mathrm{Zr}^{4+}$ content is around $7.1 \%$.

To rule out the possible size effects on the optical properties, the undoped $\mathrm{NaGdF}_{4}: \mathrm{Yb}, \mathrm{Er}$ nanocrystals of $13.2 \mathrm{~nm}$ were prepared, as shown in Figure S2a, for comparing with the $\mathrm{Zr}^{4+}$ doped $\mathrm{NaGdF}_{4}: \mathrm{Yb}$,Er with $\mathrm{Zr}^{4+}$ level of 9.9\%. The enhancement factors for up-conversion emission at $541 \mathrm{~nm}$ and downconversion emission at $1,525 \mathrm{~nm}$ were determined to be 1.2 and 1.1, respectively, as shown in Figure $\mathbf{S} \mathbf{2} \mathbf{b}$, remarkably smaller than that obtained upon $\mathrm{Zr}^{4+}$ doping. Therefore, it is reasonable 
to deduce that the enhancement effects on both up- and down-conversion luminescence may come from the alternation of crystal field symmetry surrounding $\mathrm{Er}^{3+}$ ions, induced by the $\mathrm{Zr}^{4+}$ dopants. Regarding the difference in the enhancement effects of $\mathrm{Zr}^{4+}$ ions on up- and down-conversion emissions, it can reasonably be attributed to the difference between the transitions involved in these two types emissions, as shown in Figure 2b. The up-conversion luminescence of $\mathrm{Er}^{3+}$ is a multiphoton process and requires the participation of multiple energy levels, while the down-conversion emission of $\mathrm{Er}^{3+}$ involves less energy levels. Therefore, it can be expected that the up-conversion luminescence is more readily disturbed by the crystal field.

To provide more evidence on the variation of the crystal field induced by $\mathrm{Zr}^{4+}$ ions, time-resolved luminescence measurements were carried out to determine the variations in the lifetimes of up- and down-conversion luminescence upon $\mathrm{Zr}^{4+}$ doping. The luminescence decay curves measured at different emission positions, i.e., $541 \mathrm{~nm}\left({ }^{4} \mathrm{~S}_{3 / 2}-{ }^{4} \mathrm{I}_{15 / 2}\right)$, $656 \mathrm{~nm}\left({ }^{4} \mathrm{~F}_{9 / 2}{ }^{4} \mathrm{I}_{15 / 2}\right)$, and $1,525 \mathrm{~nm}\left({ }^{4} \mathrm{I}_{13 / 2}-{ }^{4} \mathrm{I}_{15 / 2}\right)$ of the $\mathrm{Zr}^{4+}$-doped $\mathrm{NaGdF}_{4}: \mathrm{Yb}$,Er nanocrystals with different $\mathrm{Zr}^{4+}$ doping levels are shown in Figures 2 c,d. All decay curves were well-fitted with a two-exponential function and the detailed fitting results are given in Table S2. In brief, $\mathrm{Zr}^{4+}$ doping increased the average lifetime of $541 \mathrm{~nm}$ emission from $82.1 \mu \mathrm{s}$ for the undoped ones to $114.1 \mu \mathrm{s}$ for doped ones with $\mathrm{Zr}^{4+}$ content of $7.1 \%$, while the average lifetime of $1,525 \mathrm{~nm}$ emission was prolonged from $855.0 \mu$ s to 1247.2 $\mu \mathrm{s}$ accordingly. The measured lifetime of the excited states of $\mathrm{Er}^{3+}$ is the reciprocal of the total transition rate including radiative and non-radiative transition rates. The non-radiative transition rate of $\mathrm{Er}^{3+}$ can be affected by the phonon energy of $\mathrm{NaGdF}_{4}$ lattice, the energy transfer process from adsorbed photoenergy to surroundings, the cross-relaxation between energy levels, and so forth. While the radiative transition part strongly depends on the crystal structure and the symmetry of local crystal field of the emitters owing to a decrease of the forbidden nature of the transition in asymmetric sites (Boyer et al., 2004; Tu et al., 2013). In general, the lifetime of the intermediate states of activator experiences a prolongation with the distortion of its local asymmetry (Kar and Patra, 2012; Dong et al., 2015). Therefore, the prolongation of the lifetimes of both up- and down-conversion luminescence suggests that long-lived intermediate excited states ${ }^{4} \mathrm{I}_{11 / 2}$ and the population of ${ }^{4} \mathrm{~S}_{3 / 2}$ and ${ }^{4} \mathrm{I}_{13 / 2}\left(\mathrm{Er}^{3+}\right)$ become more favorable upon the introduction of $\mathrm{Zr}^{4+}$ dopants, which as a result increases the $\mathrm{f}-\mathrm{f}$ transition probability of $\mathrm{Er}^{3+}$ to induce efficient up- and down-conversion luminescence.

Trivalent lanthanide ions generally suffer from low luminescence efficiency as the electric-dipole transition within the $4 \mathrm{f}$ electrons is forbidden by Laporte rule. The non-Ln ions doping may disturb the local crystal field of the emitters and thus change the transition probability (Chen et al., 2014; Han et al., 2014). In order to further understand the underlying mechanism of the $\mathrm{Zr}^{4+}$ dopants governing the luminescence, the electric-dipole transition theory was discussed below.
The f-f transition intensity can be estimated from Judd-Ofelt theory as given by Equations (1) and (2) (Werts et al., 2002; Du et al., 2018),

$$
\begin{array}{r}
A=\frac{64 \pi^{4} e^{2}}{3 h(2 J+1) \lambda^{3}}\left[\frac{n\left(n^{2}+2\right)^{2}}{9} S_{e d}+n^{3} S_{m d}\right] \\
S_{e d}=\sum_{t=2,4,6} \Omega_{t}\left|\left\langle f^{n}[S, L] J\left\|U^{t}\right\| f^{n}\left[S^{\prime}, L^{\prime}\right] J^{\prime}\right\rangle\right|^{2}
\end{array}
$$

where $A$ is the spontaneous emission probability of transition from the initial $J$ manifold $|[S, L] J\rangle$ to final $J^{\prime}$ manifold $\left|\left[S^{\prime}, L^{\prime}\right] J^{\prime}\right\rangle$ and $e, h, n$, and $\lambda$ refer to the elementary charge, Plank constant, refraction index, and average wavelength of the transition, respectively. $2 J+1$ is the degeneracy of the initial state, and $S_{\text {ed }}$ and $S_{\mathrm{md}}$ are the electric dipole and magnetic dipole line strengths, respectively. The electric dipole transition strength $S_{\text {ed }}$ is very sensitive to the chemical surrounding of the lanthanide emitting ions, whereas the magnetic dipole transition strength $S_{\text {md }}$ is not. In Equation (2), $S_{\text {ed }}$ can be calculated by three transition intensity parameters $\Omega_{t}(t=2,4,6) . \Omega_{2}$ is the spectral intensity parameter of electric-dipole transition for $4 \mathrm{f}^{\mathrm{n}}$ electron configuration, strongly depending on the crystal field environment and reflecting that the asymmetry of the crystal field surrounding lanthanide emitting ions (Zhang et al., 2018). In principle, the enhanced lattice distortion leads to lower local crystal field symmetry, thereby giving rise to larger value of $\Omega_{2}$ (Walsh et al., 1998; Liu et al., 2008). With relatively smaller cationic radius and higher valence state of $\mathrm{Zr}^{4+}$ compared with those of $\mathrm{Gd}^{3+}$, the bond length of $\mathrm{Zr}-\mathrm{F}(1.90 \AA)$ is shorter than that of Gd-F (1.99 $\AA$ ), whilst the bond energy of $\mathrm{Zr}$ F $(627.2 \mathrm{~kJ} / \mathrm{mol})$ is higher than that of $\mathrm{Gd}-\mathrm{F}(590 \mathrm{~kJ} / \mathrm{mol})$, indicating that $\mathrm{Zr}^{4+}$ ions have stronger electron cloud distortion ability than $\mathrm{Gd}^{3+}$ ions. This can be further evidenced by a stronger electronic polarizability of $\mathrm{Zr}^{4+}\left(3.56 \times 10^{-24} \mathrm{~cm}^{3}\right)$ than that of $\mathrm{Gd}^{3+}\left(3.39 \times 10^{-24} \mathrm{~cm}^{3}\right)$ (Shannon and Fischer, 2016). Therefore, the distortion of electron clouds of $\mathrm{Er}^{3+}$ ions becomes favorable upon substitution of $\mathrm{Gd}^{3+}$ with $\mathrm{Zr}^{4+}$ dopants, which is intensified against the $\mathrm{Zr}^{4+}$ doping level. The decreased local crystal field symmetry is expected to give rise to a higher $\Omega_{2}$, which consequently encourages the electronic coupling between $4 \mathrm{f}$ energy levels and increases the probability of the intra $\mathrm{f}-\mathrm{f}$ transition, leading to more effective enhancement in up-conversion emission.

\section{$\mathrm{NaGdF}_{4}: \mathrm{Yb}, \mathrm{Er}$ Nanocrytals Doped With Cations of Various Valance States}

To further show the effects of the valence state of cationic dopants on the emission of $\mathrm{Er}^{3+}$ ions via the modulation of the local crystal field, non-Ln cations with various valance states, e.g., $\mathrm{Sc}^{3+}, \mathrm{Mg}^{2+}, \mathrm{Mn}^{2+}$, were also chosen to dope the $\mathrm{NaGdF}_{4}: \mathrm{Yb}, \mathrm{Er}$ nanocrystals by feeding molar ratio of $10 \%$, according to that optimized for $\mathrm{Zr}^{4+}$.

Although $\mathrm{Sc}^{3+}$ ion has the same valence as $\mathrm{Gd}^{3+}$ ion, it was selected to dope $\mathrm{NaGdF}_{4}: \mathrm{Yb}, \mathrm{Er}$ by substituting $\mathrm{Gd}^{3+}$ ion. As it possesses no electron in $d$ orbital, the substitution won't introduce new energetic levels into the nanocrystals. As 

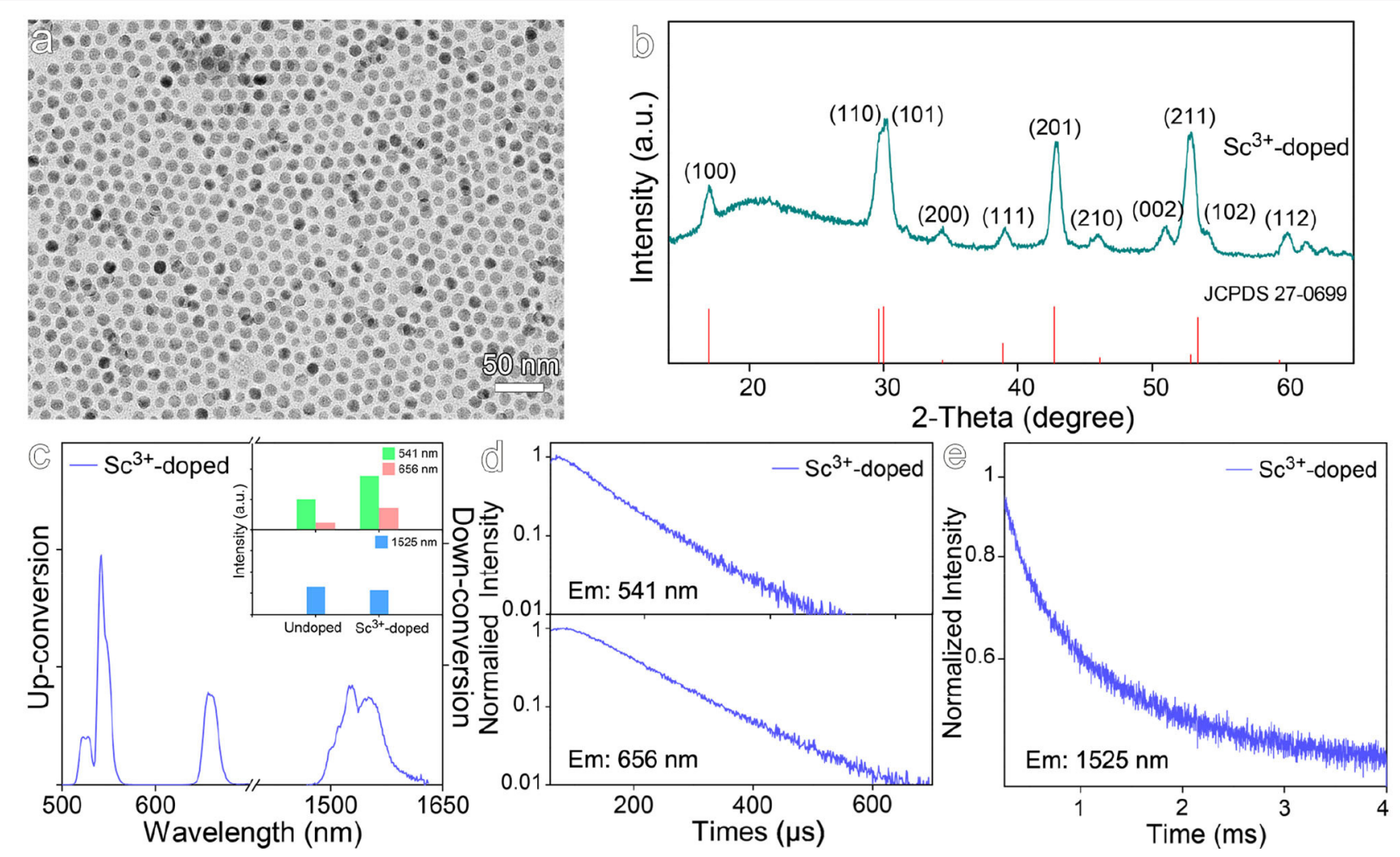

FIGURE 3 | (a) TEM image and (b) corresponding XRD pattern of $\mathrm{Sc}^{3+}$-doped $\mathrm{NaGdF}_{4}$ :Yb,Er nanocrystals. (c) The up- and down-conversion luminescence spectra and intensities at 541, 656, and 1,525 nm of Sc ${ }^{3+}$-doped NaGdF 4 :Yb,Er nanocrystals under 980 nm laser excitation. (d,e) Transient emissions observed at 541, 656, and $1,525 \mathrm{~nm}$ of $\mathrm{Sc}^{3+}$-doped $\mathrm{NaGdF}_{4}: \mathrm{Yb}$, Er nanocrystal.

shown in Figure 3a, the particle size of the resulting $\mathrm{Sc}^{3+}$. doped nanocrystals is $12.6 \pm 0.8 \mathrm{~nm}$. The XRD pattern shown in Figure $\mathbf{3 b}$ reveals the nanocrystals are in hexagonal phase. According to the luminescence spectra given in Figure $3 \mathbf{c}, \mathrm{Sc}^{3+}$ doping only slightly increases the up-conversion luminescence by a factor of 1.8 and shows almost no impact on the down-conversion luminescence. As shown in Figures 3d,e and Table S3, $\mathrm{Sc}^{3+}$ doping gives rise to a slight increase in the average lifetimes of $541 \mathrm{~nm}$ and $656 \mathrm{~nm}$ emissions, i.e., from $82.1 \mu \mathrm{s}$ to $85.9 \mu \mathrm{s}$ and from $98.7 \mu \mathrm{s}$ to $118.1 \mu \mathrm{s}$, respectively. The average lifetime of down-conversion emission at $1,525 \mathrm{~nm}$ was increased from $855.0 \mu \mathrm{s}$ to $1035.9 \mu \mathrm{s}$, but still lower than that for $\mathrm{Zr}^{4+}$-doped counterparts. This can be understood by the fact that $\mathrm{Sc}^{3+}$ has very similar properties to $\mathrm{Gd}^{3+}$ as seen by very comparable binding energies between Sc-F $(599 \mathrm{~kJ} / \mathrm{mol})$ and $\mathrm{Gd}-$ $\mathrm{F}(590 \mathrm{~kJ} / \mathrm{mol})$ bonds, thus it won't introduce strong distortion effects on the crystal field surrounding $\mathrm{Er}^{3+}$ as $\mathrm{Zr}^{4+}$ does.

Both $\mathrm{Mg}^{2+}$ and $\mathrm{Mn}^{2+}$ were selected to dope $\mathrm{NaGdF}_{4}: \mathrm{Yb}, \mathrm{Er}$ nanocrystals, because the former is free of $d$ orbital electrons contrasting to the latter that has $d^{5}$ electron configuration. Therefore, it is expected to show the impacts of electronic configuration of the dopants on the optical properties of the resulting nanocrystals. As shown in Figures $\mathbf{4 a}, \mathbf{b}$, the particle sizes of the resulting $\mathrm{Mg}^{2+}$-doped and $\mathrm{Mn}^{2+}$-doped nanocrystals are of $12.4 \pm 1.0 \mathrm{~nm}$ and $7.2 \pm 1.0 \mathrm{~nm}$, respectively. The XRD results shown in Figure $4 c$ reveal that $\mathrm{Mg}^{2+}$-doped nanocrystals display a hexagonal phase structure, while $\mathrm{Mn}^{2+}$. doped nanocrystals exhibit a distinct cubic phase structure. The results in Figure 4d further reveal that $\mathrm{Mg}^{2+}$ doping slightly decreases the emission at $541 \mathrm{~nm}$ and the emission at $1,525 \mathrm{~nm}$, while the emission intensity at $656 \mathrm{~nm}$ remains nearly unchanged. This can be explained by the fact that $\mathrm{Mg}^{2+}$ ions have much weaker electron cloud distortion ability than $\mathrm{Gd}^{3+}$ due to low electric polarizability $\left(0.6 \times 10^{-24} \mathrm{~cm}^{3}\right)$, and thereby $\mathrm{Mg}^{2+}$-doped nanocrystals display even weakened luminescence in comparison with the undoped $\mathrm{NaGdF}_{4}: \mathrm{Yb}, \mathrm{Er}$ nanocrystals. As shown in Figures 4e, $\mathbf{f}$ and Table S3, $\mathrm{Mg}^{2+}$ dopants give rise to a slightly increased average lifetimes for $541 \mathrm{~nm}$ and $656 \mathrm{~nm}$ emissions, i.e., from $82.1 \mu \mathrm{s}$ to $87.4 \mu \mathrm{s}$ and $98.7 \mu \mathrm{s}$ to $115.4 \mu \mathrm{s}$ in comparison with the undoped one. The average lifetime of down-conversion emission at $1,525 \mathrm{~nm}$ was increased from $855.0 \mu \mathrm{s}$ to $962.8 \mu \mathrm{s}$, even shorter than that of $\mathrm{Sc}^{3+}$-doped nanocrystals let alone the lifetime of $\mathrm{Zr}^{4+}$-doped ones. Therefore, it can be concluded that $\mathrm{Mg}^{2+}$ ions can hardly distort the crystal filed surrounding $\mathrm{Er}^{3+}$ ions. Moreover, the substitution of $\mathrm{Ln}^{3+}$ ions with bivalent $\mathrm{Mg}^{2+}$ ions in the $\mathrm{NaGdF}_{4}: \mathrm{Yb}, \mathrm{Er}$ nanocrystals will generate $\mathrm{F}^{-}$vacancies to balance the charge of the whole 


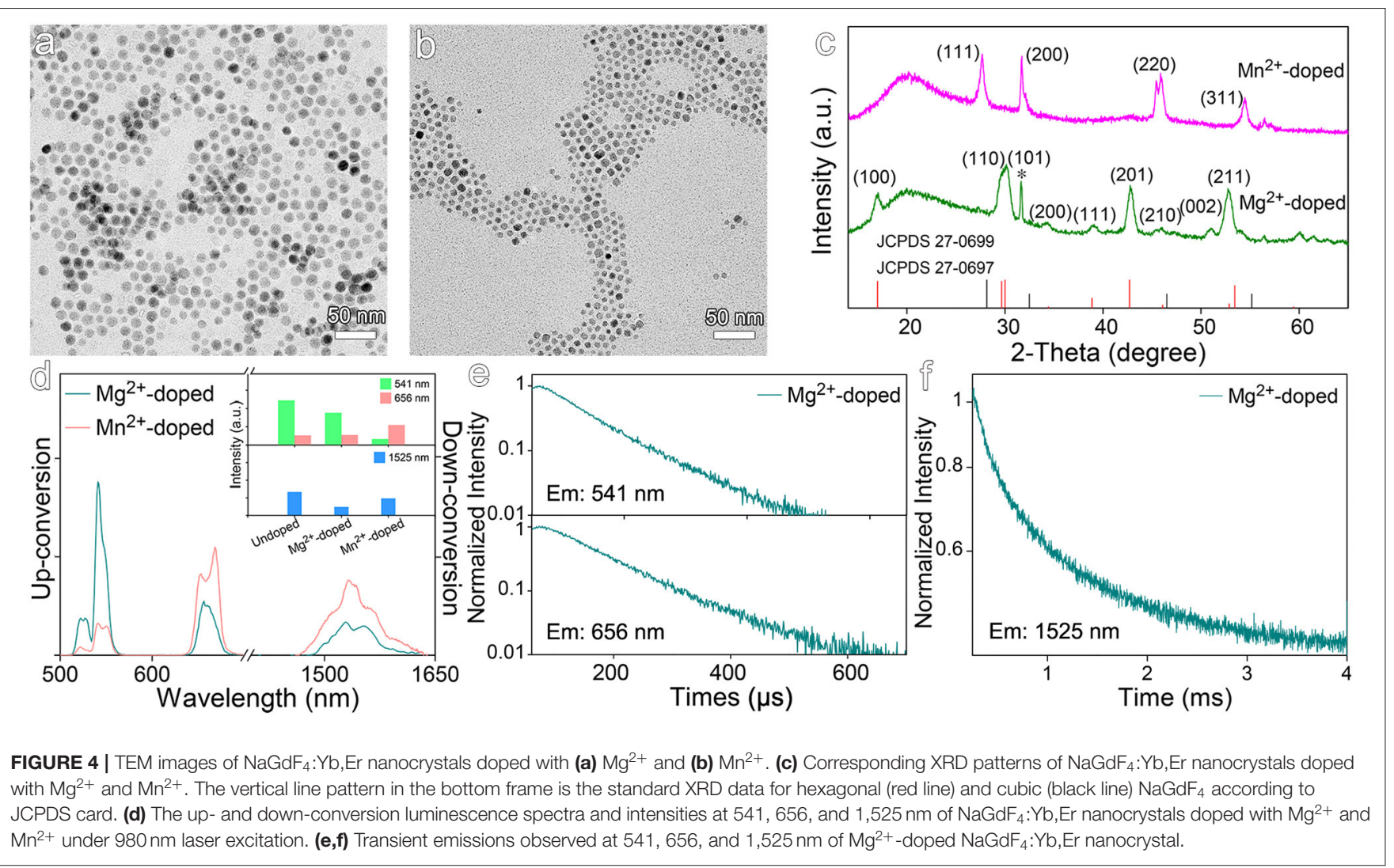

nanocrystal, which is even deleterious to the luminescence as the increase of the concentration of defects around the emitters (Tang et al., 2020a).

When it comes to $\mathrm{Mn}^{2+}$ dopants, the intensity of $541 \mathrm{~nm}$ emission is dramatically decreased by a factor of 7.5 , while the intensity of $656 \mathrm{~nm}$ emission is increased by a factor of 2.1 , in comparison with those recorded from undoped counterparts. Consequently, the ratio of red emission to green emission is dramatically increased as shown in Figure 4d, arising from the involvement of $d$ electron-associated energy levels of $\mathrm{Mn}^{2+}$ ions. It has been reported that using $\mathrm{KMnF}_{3}$ as matrix, a single-band red emission was obtained upon Mn-doping (Wang et al., 2011). Although the intensity of $1,525 \mathrm{~nm}$ emission is nearly unchanged in comparison with that of undoped nanocrystals, the downconversion emission profile of $\mathrm{Er}^{3+}$ ions is also varied upon $\mathrm{Mn}^{2+}$ doping.

\section{$\mathrm{NaGdF}_{4}: \mathrm{Yb}, \mathrm{Er}$ Nanocrystals Doped With Univalent lons}

Different from the above-mentioned mechanism for enhancing the luminescence of $\mathrm{Er}^{3+}$ emitters through the distortion of local crystal field, univalent ions such as $\mathrm{Li}^{+}$and $\mathrm{K}^{+}$were also used to dope $\mathrm{NaGdF}_{4}: \mathrm{Yb}, \mathrm{Er}$ nanocrystals by substituting $\mathrm{Na}^{+}$ rather than $\mathrm{Gd}^{3+}$. The TEM results shown in Figures 5a,b reveal that the average size of $\mathrm{Li}^{+}$-doped nanocrystals is of $14.3 \pm$
$1.2 \mathrm{~nm}$, while that of $\mathrm{K}^{+}$-doped nanocrystals becomes greatly decreased to $6.8 \pm 1.0 \mathrm{~nm}$. The XRD results in Figure $5 \mathrm{c}$ reveal that $\mathrm{Li}^{+}$-doped nanocrystals are in hexagonal phase, but $\mathrm{K}^{+}$doped nanocrystals are in cubic phase. As the diffraction peak of (201) crystal plane of $\mathrm{Li}^{+}$-doped $\mathrm{NaGdF}_{4}: \mathrm{Yb}, \mathrm{Er}$ shifts higher angles, it can be deduced that $\mathrm{Li}^{+}$ions take the positions of $\mathrm{Na}^{+}$ions rather than occupy the interstitial sites. According to luminescence spectra of the $\mathrm{Li}^{+}$- and $\mathrm{K}^{+}$-doped $\mathrm{NaGdF}_{4}: \mathrm{Yb}, \mathrm{Er}$ nanocrystals shown in Figure 5d, $\mathrm{Li}^{+}$doping increases the intensities of $541 \mathrm{~nm}$ emission and $1,525 \mathrm{~nm}$ emission by factors of 6.8 and 2.5, respectively. In huge contrast, the up- and down-conversion luminescence of $\mathrm{K}^{+}$-doped nanocrystals are dramatically decreased, due to the remarkably decreased particle size and higher crystal field symmetry of cubic phase. As shown in Figures 5e,f and Table S4, $\mathrm{Li}^{+}$doping significantly prolongs the average lifetimes of emissions at 541 and $656 \mathrm{~nm}$, i.e., from $82.1 \mu$ s to $107.5 \mu \mathrm{s}$, and from $98.7 \mu$ s to $151.1 \mu \mathrm{s}$, respectively. Meanwhile, $\mathrm{Li}^{+}$doping also profoundly prolongs the average lifetime of the emission at $1,525 \mathrm{~nm}$, i.e., from $855.0 \mu \mathrm{s}$ to $1297.5 \mu \mathrm{s}$, which is comparable with $1247.2 \mu \mathrm{s}$ for $\mathrm{Zr}^{4+}$-doped ones. In fact, owing to the much smaller radius of $\mathrm{Li}^{+}(0.76$ $\AA)$ than that of $\mathrm{Na}^{+}(1.02 \AA)$, the substitution of $\mathrm{Na}^{+}$with $\mathrm{Li}^{+}$in $\mathrm{NaGdF}_{4}$ nanocrystals can thus effectively modulate the crystal field, which is also supported by the higher binding energy of Li-F bond $(577 \mathrm{~kJ} / \mathrm{mol})$ than that of $\mathrm{Na}-\mathrm{F}$ bond $(477$ $\mathrm{kJ} / \mathrm{mol}$ ). Therefore, doping $\mathrm{Li}^{+}$into $\mathrm{NaGdF}_{4}: \mathrm{Yb}, \mathrm{Er}$ is favorable 

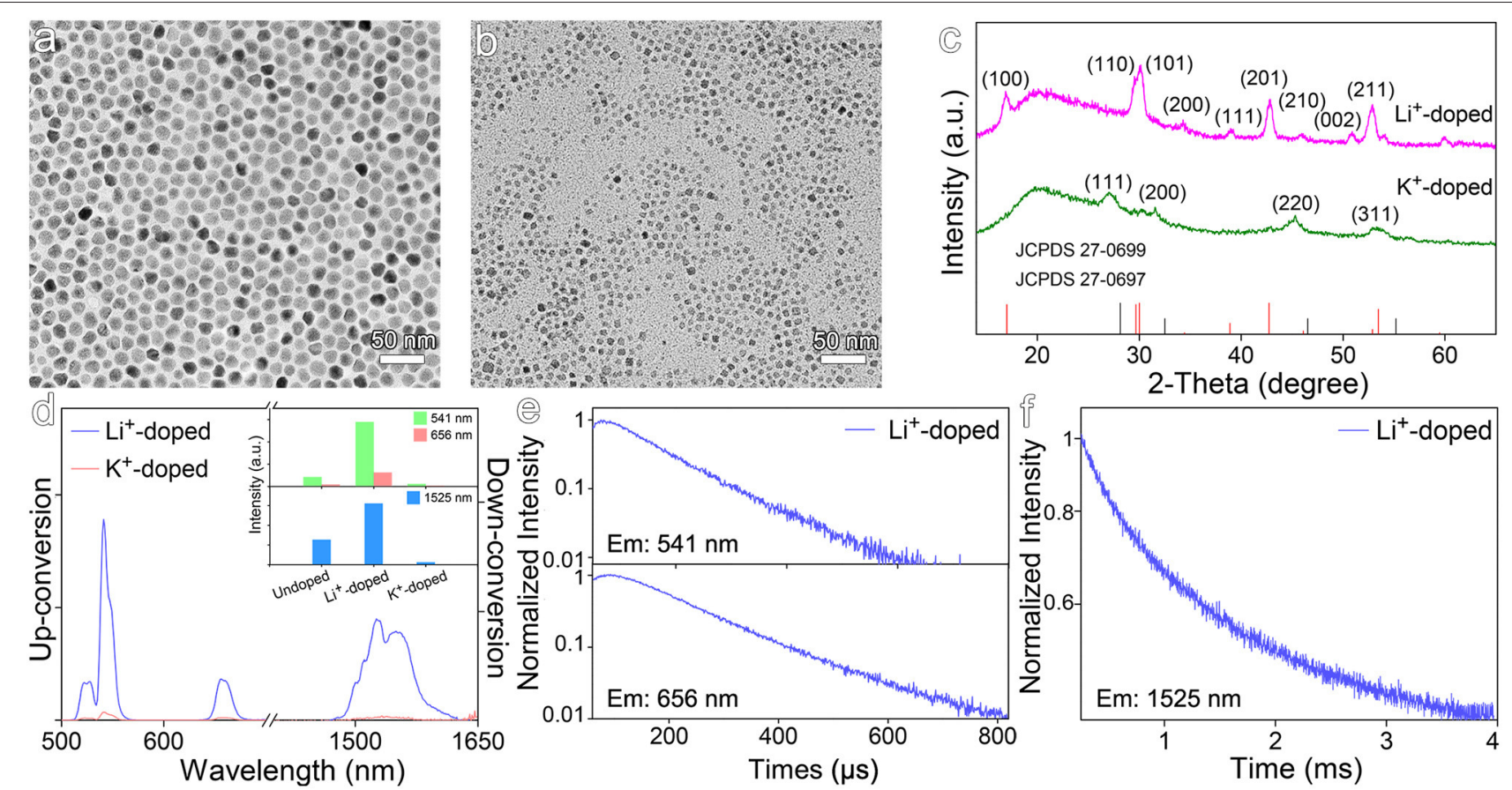

FIGURE 5 | TEM images of NaGdF $:$ Yb,Er nanocrystals doped with (a) $\mathrm{Li}^{+}$and (b) $\mathrm{K}^{+}$. (c) Corresponding XRD patterns of NaGdF $\mathrm{N}_{4}$ Yb,Er nanocrystals doped with

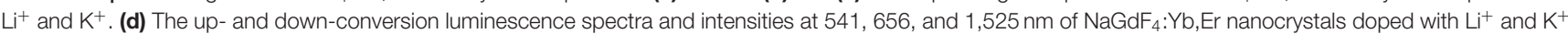
under 980 nm laser excitation, respectively. (e,f) Transient emissions observed at 541, 656, and 1,525 nm of Li+-doped NaGdF

for enhancing both up- and down-conversion luminescence, similar to $\mathrm{Zr}^{4+}$ dopants.

\section{The Synergistic Crystal Field Modulation via Co-doping of $\mathrm{Zr}^{4+}$ and $\mathrm{Li}^{+}$}

Considering $\mathrm{Zr}^{4+}$ and $\mathrm{Li}^{+}$ions occupy the different lattice sites, it's therefore very interesting to synergistically combine the effects of both $\mathrm{Zr}^{4+}$ and $\mathrm{Li}^{+}$ions for further improving the optical properties of the $\mathrm{NaGdF}_{4}$ : $\mathrm{Yb}, \mathrm{Er}$ nanocrystals. The co-doped nanocrystals were then prepared. The TEM image and selected area electron diffraction pattern of the resulting nanocrystals shown in Figure 6a reveal that the average size is $15.8 \pm 1.2 \mathrm{~nm}$ and the nanocrystals are in hexagonal phase. As shown in Figure 6b, upon co-doping of $\mathrm{Zr}^{4+}$ and $\mathrm{Li}^{+}$ions, the luminescence intensity of up-conversion emission at $541 \mathrm{~nm}$ is enhanced by factors of 15.0, 2.2, and 2.2, if compared with those recorded from undoped, $\mathrm{Li}^{+}$-doped, and $\mathrm{Zr}^{4+}$-doped nanocrystals, respectively, while the down-conversion emission intensity of co-doped samples is enhanced by factors of 2.7, 1.1, and 1.5, respectively. As shown in Figures 6c,d and Table S5, the transient optical behaviors of the co-doped nanocrystals also confirm the synergistic effects of $\mathrm{Zr}^{4+}$ and $\mathrm{Li}^{+}$, evidenced by the prolonged average decay lifetimes for different emissions. For example, the decay lifetime of $541 \mathrm{~nm}$ emission is of $123.3 \mu \mathrm{s}$, higher than $82.1 \mu \mathrm{s}$ for the undoped, $107.5 \mu \mathrm{s}$ for $\mathrm{Li}^{+}$-doped, and $114.1 \mu$ s for $\mathrm{Zr}^{4+}$-doped ones.

\section{CONCLUSION}

In summary, tetravalent $\mathrm{Zr}^{4+}$-doped $\mathrm{NaGdF}_{4}$ : $\mathrm{Yb}$,Er nanocrystals were prepared. The steady-state and transient luminescence spectroscopies studies demonstrated that the $\mathrm{Zr}^{4+}$ dopants could simultaneously enhance both up- and down-conversion luminescence of $\mathrm{Er}^{3+}$ ions. Combining the experimental results with Judd-Ofelt theoretical analysis, it was revealed that $\mathrm{Zr}^{4+}$ dopants take effects by varying the crystal field surrounding $\mathrm{Er}^{3+}$ emitters. Compared with host $\mathrm{Gd}^{3+}$ ion, $\mathrm{Zr}^{4+}$ ion exhibits increased electron cloud distortion ability due to its stronger electric polarizability and higher bond energy with $\mathrm{F}^{-}$, which accounts for the increased distortion of crystal field surrounding $\mathrm{Er}^{3+}$, thus efficiently enhancing both up- and down- conversion luminescence. In addition, the effects of non- $\mathrm{Ln}$ dopants $\mathrm{Sc}^{3+}$, $\mathrm{Mg}^{2+}, \mathrm{Mn}^{2+}$ ) on the up- and down-conversion emission were also investigated, and no stronger effects than $\mathrm{Zr}^{4+}$ ion were observed. Apart from the substituting $\mathrm{Gd}^{3+}$ ion, strong luminescence enhancement effects were also found when $\mathrm{Li}^{+}$ion was used to substitute $\mathrm{Na}^{+}$via similar mechanism, which offers an opportunity to show the synergistic effects of $\mathrm{Zr}^{4+}$ and $\mathrm{Li}^{+}$ ions by co-doping the $\mathrm{NaGdF}_{4}: \mathrm{Yb}, \mathrm{Er}$ nanocrystals with them. Upon optimization, the up-conversion emissions were enhanced by more than one order of magnitude compared with undoped nanocrystals. The current studies thus demonstrate that the local crystal field surrounding emitters is an effective parameter for manipulating the up- and down-conversion luminescence of lanthanide emitters. 

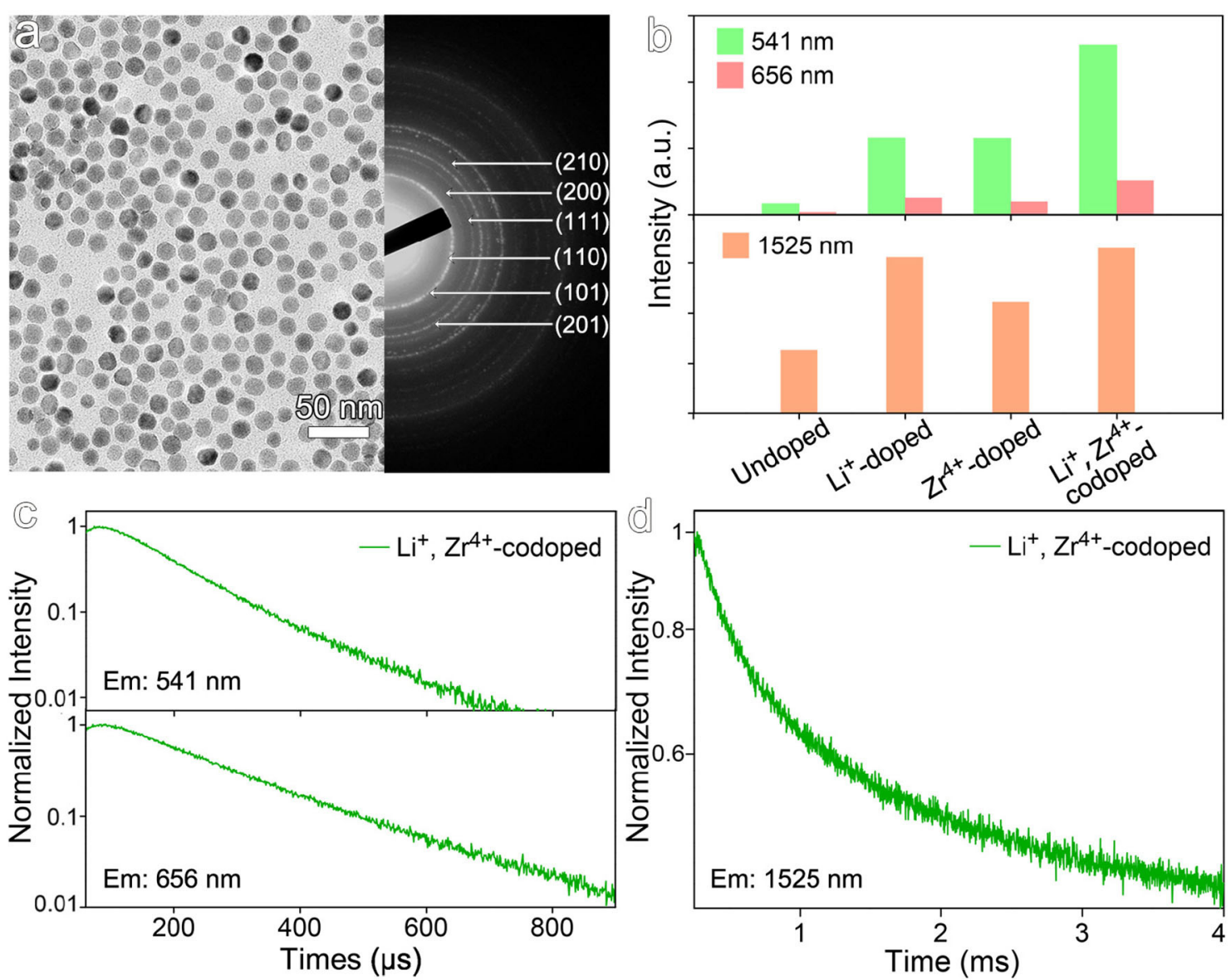

FIGURE 6 | (a) TEM image and selected area electron diffraction pattern of NaGdF 4 :Yb,Er nanocrystals co-doped with $\mathrm{Li}^{+}$and $\mathrm{Zr}^{4+}$. (b) The emission intensities at 541, 656, and 1,525 nm of $\mathrm{NaGdF}_{4}: Y b$,Er nanocrystals co-doped with $\mathrm{Li}^{+}$and $\mathrm{Zr}^{4+}$ under $980 \mathrm{~nm}$ laser excitation. (c,d) Transient emissions observed at 541, 656, and $1,525 \mathrm{~nm}$ of $\mathrm{NaGdF}_{4}: \mathrm{Yb}, \mathrm{Er}$ nanocrystals co-doped with $\mathrm{Li}^{+}$and $\mathrm{Zr}^{4+}$ under $980 \mathrm{~nm}$ laser excitation.

\section{MATERIALS AND METHODS}

\section{Materials}

$\mathrm{GdCl}_{3} \cdot 6 \mathrm{H}_{2} \mathrm{O}(450855), \quad \mathrm{YbCl}_{3} \cdot 6 \mathrm{H}_{2} \mathrm{O}(337927), \quad \mathrm{ErCl}_{3} \cdot 6 \mathrm{H}_{2} \mathrm{O}$ (259256), $\mathrm{ScCl}_{3} \cdot 6 \mathrm{H}_{2} \mathrm{O}$ (451274), oleic acid (OA, 364525), 1octadecene (ODE, O806), oleylamine (OM, O7805), ammonium fluoride $\left(\mathrm{NH}_{4} \mathrm{~F}, 216011\right)$ and potassium fluoride $(\mathrm{KF}, 402931)$ were all purchased from Sigma-Aldrich. $\mathrm{LiOH} \cdot \mathrm{H}_{2} \mathrm{O}(80074718)$, $\mathrm{MgCl}_{2} \cdot 6 \mathrm{H}_{2} \mathrm{O}(10012817)$ and $\mathrm{Mn}(\mathrm{ac})_{2} \cdot 4 \mathrm{H}_{2} \mathrm{O}(\mathrm{A} 22100702)$ were purchased from Sinopharm Chemical Reagent Beijing, Co., Ltd. $\mathrm{Zr}(\mathrm{acac})_{4}(\mathrm{Z107220})$ was purchased from Aladdin Chemistry Co., Ltd. Other analytical grade chemicals, such as cyclohexane, ethanol and sodium hydroxide, were purchased from Sinopharm Chemical Reagent Beijing, Co., Ltd.

\section{Synthesis of $\mathrm{NaGdF}_{4}: \mathrm{Yb}, \mathrm{Er}$ Nanocrystals}

The $\mathrm{NaGdF}_{4}: \mathrm{Yb}, \mathrm{Er}$ nanocrystals were synthesized through the coprecipitation reaction at high temperature according to our previous works with slight modification (Liu et al., 2016). Typically, $\mathrm{GdCl}_{3} \cdot 6 \mathrm{H}_{2} \mathrm{O}(0.48 \mathrm{mmol}), \mathrm{YbCl}_{3} \cdot 6 \mathrm{H}_{2} \mathrm{O}$ $(0.108 \mathrm{mmol})$, and $\mathrm{ErCl}_{3} \cdot 6 \mathrm{H}_{2} \mathrm{O}(0.012 \mathrm{mmol})$ were mixed with $4 \mathrm{~mL}$ of $\mathrm{OA}$ as the coordinating ligand and $16 \mathrm{~mL}$ of ODE as the non-coordinating solvent in a $100 \mathrm{~mL} 3$ necked flask. The mixture was heated to $150^{\circ} \mathrm{C}$ under a vacuum and then kept at this temperature approximately for $60 \mathrm{~min}$ for forming a homogeneous solution. $10 \mathrm{~mL}$ of methanol solution containing $\mathrm{NaOH}(1.8 \mathrm{mmol})$ and $\mathrm{NH}_{4} \mathrm{~F}$ $(1.8 \mathrm{mmol})$ was added dropwise after the solution was cooled down to $50^{\circ} \mathrm{C}$. Then the reaction system was stirred at $50^{\circ} \mathrm{C}$ for another $30 \mathrm{~min}$. After that, the methanol was removed under a vacuum and the solution was kept at $110^{\circ} \mathrm{C}$ for $10 \mathrm{~min}$ until there were no bubbles in the reaction system. Subsequently, the reaction temperature was improved to $300^{\circ} \mathrm{C}$ with the rate of $20^{\circ} \mathrm{C} / \mathrm{min}$, under a gentle flow of nitrogen protection. And the reaction was held for $1 \mathrm{~h}$ at $300^{\circ} \mathrm{C}$. Finally, the reaction system was cooled to room temperature. The nanocrystals were precipated by ethanol, collected by centrifugation for several times and then re-dispersed in cyclohexane for further use.

\section{Synthesis of Non-In lons Doped $\mathrm{NaGdF}_{4}: \mathrm{Yb}, \mathrm{Er}$ Nanocrystals}

The rare-earth nanocrystals doped with different non-Ln metal ions were synthesized following a similar process of 
the preparation of $\mathrm{NaGdF}_{4}: \mathrm{Yb}, \mathrm{Er}$ nanocrystals. In the case of $\mathrm{Zr}^{4+}$-doped $\mathrm{NaGdF}_{4}: \mathrm{Yb}$,Er nanocrystals, different feeding ratios of $\mathrm{Zr}^{4+}$ ions (defined as the molar ratios of $\mathrm{Zr}^{4+}$ precursor to the amount of total cation precursors) were used, namely: $3.0,5.0,10.0,15.0 \%$. In detail, $\mathrm{Zr}(\mathrm{acac})_{4}(x$ mmol, $x=0.018,0.03,0.06,0.09), \mathrm{GdCl}_{3} \cdot 6 \mathrm{H}_{2} \mathrm{O}(0.48-x$ $\mathrm{mmol}), \mathrm{YbCl}_{3} \cdot 6 \mathrm{H}_{2} \mathrm{O}(0.108 \mathrm{mmol})$, and $\mathrm{ErCl}_{3} \cdot 6 \mathrm{H}_{2} \mathrm{O}(0.012$ mmol) were mixed with $4 \mathrm{~mL}$ of $\mathrm{OA}$ and $16 \mathrm{~mL}$ of ODE in a $100 \mathrm{~mL}$ 3-necked flask. While the $\mathrm{Sc}^{3+}, \mathrm{Mg}^{2+}$ or $\mathrm{Mn}^{2+}$-doped $\mathrm{NaGdF}_{4}: \mathrm{Yb}, \mathrm{Er}$ nanocrystals were synthesized similar to the $\mathrm{Zr}^{4+}$-doped nanocrystals $\left(\mathrm{Zr}^{4+}\right.$ precursor:10.0\%) by replacing $\mathrm{Zr}(\mathrm{acac})_{4}$ with $\mathrm{ScCl}_{3} \cdot 6 \mathrm{H}_{2} \mathrm{O}, \mathrm{MgCl}_{2} \cdot 6 \mathrm{H}_{2} \mathrm{O}$ or $\mathrm{Mn}(\mathrm{ac})_{2} \cdot 4 \mathrm{H}_{2} \mathrm{O}$, respectively. In addition, for the $\mathrm{Mn}^{2+}$. doped $\mathrm{NaGdF}_{4}: \mathrm{Yb}$,Er nanoparticles, the precursors were mixed with $3.8 \mathrm{~mL}$ of $\mathrm{OA}$ and $0.2 \mathrm{~mL} \mathrm{OM}$ as the coordinating ligand. The growth of the nanocrystals and the following purification procedures were the same as those for the $\mathrm{NaGdF}_{4}: \mathrm{Yb}$,Er nanocrystals.

In the case of $\mathrm{Li}^{+}$-doped $\mathrm{NaGdF}_{4}$ :Yb,Er nanocrystals, after forming a homogeneous solution of rare-earth chloride at $50^{\circ} \mathrm{C}, 10 \mathrm{ml}$ of methanol solution containing of $\mathrm{NaOH}(1.62$ $\mathrm{mmol}), \mathrm{LiOH} \cdot \mathrm{H}_{2} \mathrm{O}(0.18 \mathrm{mmol})$ and $\mathrm{NH}_{4} \mathrm{~F}(1.8 \mathrm{mmol})$ was added in the reaction system for preparing $\mathrm{Li}^{+}$-doped $\mathrm{NaGdF}_{4}: \mathrm{Yb}, \mathrm{Er}$ nanocrystals. Other experimental steps were the same to the synthesis of above-mentioned nanocrystals. While in the case of $\mathrm{NaGdF}_{4}: \mathrm{Yb}, \mathrm{Er}$ nanoparticles doped with $\mathrm{K}^{+}$, the methanol solution was consisted of $\mathrm{NaOH}$ (1.62 mmol), KF $(0.18 \mathrm{mmol})$ and $\mathrm{NH}_{4} \mathrm{~F}(1.62 \mathrm{mmol})$. Other experimental steps were the same to the synthesis of above-mentioned nanoparticles.

\section{Synthesis of $\mathrm{Li}^{+}$and $\mathrm{Zr}^{4+}$ Co-doped $\mathrm{NaGdF}_{4}: \mathrm{Yb}, \mathrm{Er}$ Nanocrystals}

$\mathrm{GdCl}_{3} \cdot 6 \mathrm{H}_{2} \mathrm{O}(0.42 \mathrm{mmol}), \mathrm{Zr}(\mathrm{acac})_{4}(0.06 \mathrm{mmol}), \mathrm{YbCl}_{3} \cdot 6 \mathrm{H}_{2} \mathrm{O}$ $(0.108 \mathrm{mmol})$, and $\mathrm{ErCl}_{3} \cdot 6 \mathrm{H}_{2} \mathrm{O}(0.012 \mathrm{mmol})$ were mixed with $4 \mathrm{~mL}$ of $\mathrm{OA}$ and $16 \mathrm{~mL}$ of ODE. After forming a homogeneous solution of rare-earth chloride at $50^{\circ} \mathrm{C}$, $10 \mathrm{ml}$ of methanol solution containing of $\mathrm{NaOH}$ (1.62 $\mathrm{mmol}), \mathrm{LiOH} \cdot \mathrm{H}_{2} \mathrm{O}(0.18 \mathrm{mmol})$ and $\mathrm{NH}_{4} \mathrm{~F}(1.8 \mathrm{mmol})$ was added in the reaction system for preparing $\mathrm{Li}^{+}$ and $\mathrm{Zr}^{4+}$ co-doped $\mathrm{NaGdF}_{4}: \mathrm{Yb}$,Er nanocrystals. Other experimental steps were the same to the synthesis of above-mentioned nanocrystals.

\section{Structural and Optical Characterization of Nanocrystals}

Transmission electron microscopy (TEM) measurements were carried out with JEM-100CXII at $100 \mathrm{KV}$ and Hitachi HT7700 at $120 \mathrm{KV}$ for characterizing the particle shape and size, and selected area electron diffractions (SAED) were taken for the characterization of crystalline structure. The particle size was determined with ImageJ by counting more than 300 nanoparticles per sample. In addition, X-ray diffraction (XRD) measurements were carried out on a Regaku D/Max2500 diffractometer under $\mathrm{Cu} \mathrm{K} \alpha_{1}$ radiation $(\lambda=1.54056 \AA)$ for further characterizing the phase structure of the resultant nanocrystals. The concentrations of metal ions in different systems was determined by using an inductively coupled plasma atomic emission spectrometer (ICP-AES 6300DV) after the particles were eroded with certain concentrated mixture of concentrated nitric acid and hydrogen peroxide. The up- and down-conversion luminescence spectra were measured by a Cary Eclipse fluorescence spectrophotometer and Edinburgh Instruments FLS 920 equipped with $980 \mathrm{~nm}$ CW laser diodes (MDL-III-980 nm) as the excitation sources, respectively. The luminescence spectra of different samples are normalized according to the concentration of $\mathrm{Er}^{3+}$ serving as the emissive centers, and the excitation power (2 $\mathrm{W} / \mathrm{cm}^{2}$ ) remain unchanged for comparing the luminescence intensities of different samples dispersed in cyclohexane. The transient up- and down-conversion luminescence of different samples dispersed in cyclohexane was recorded on FLS 920 equipped with $980 \mathrm{~nm}$ pulsed laser diodes (the excitation power: $2 \mathrm{~W} / \mathrm{cm}^{2}$, pulse frequency: $100 \mathrm{~Hz}$, pulse width: $3 \mu \mathrm{s}$ ), with the former detected by HAMAMATSU PMT (R928-P) detector and the latter detected by HAMAMATSU NIRPMT (R5509) detector.

\section{DATA AVAILABILITY STATEMENT}

All datasets generated for this study are included in the article/Supplementary Material.

\section{AUTHOR CONTRIBUTIONS}

MG, CL, LJ, and YL were responsible for designing experiments, put forward the innovation of this work, and wrote the paper. YL carried out the experiments and analyzed the data with the support from MG, LJ, and CL. All the authors contributed to the discussion of results and the design of figures.

\section{FUNDING}

This work was financially supported by the National Key Research and Development Program of China (2018YFA0208800), National Natural Science Foundation of China (NSFC) (81771902, 81720108024, 81530057, 81671755, and 81671754), the Youth Innovation Promotion Association CAS (2018042), CAS-VPST Silk Road Science Fund 2019 (GJHZ201963), and State Key Laboratory of Luminescence and Applications (SKLA-2019-01).

\section{SUPPLEMENTARY MATERIAL}

The Supplementary Material for this article can be found online at: https://www.frontiersin.org/articles/10.3389/fchem. 2020.00832/full\#supplementary-material 


\section{REFERENCES}

Ai, X., Wang, Z., Cheong, H., Wang, Y., Zhang, R., Lin, J., et al. (2019). Multispectral optoacoustic imaging of dynamic redox correlation and pathophysiological progression utilizing upconversion nanoprobes. Nat. Commun. 10:1087. doi: 10.1038/s41467-019-09001-7

Antaris, A. L., Chen, H., Cheng, K., Sun, Y., Hong, G., Qu, C., et al. (2016). A small-molecule dye for NIR-II imaging. Nat. Mater. 15, 235-242. doi: $10.1038 /$ nmat 4476

Boyer, J. C., Vetrone, F., Capobianco, J. A., Speghini, A., and Bettinelli, M. (2004). Variation of fluorescence lifetimes and judd-ofelt parameters between Eu3+doped bulk and nanocrystalline cubic $\mathrm{Lu}_{2} \mathrm{O}_{3}$. J. Phys. Chem. B 108, 20137-20143. doi: 10.1021/jp0480504

Buonsanti, R., and Milliron, D. J. (2013). Chemistry of doped colloidal nanocrystals. Chem. Mater. 25, 1305-1317. doi: $10.1021 / \mathrm{cm} 304104 \mathrm{~m}$

Chen, B. K., Susha, A. S., Reckmeier, C. J., Kershaw, S. V., Wang, Y. T., Zou, B. S., et al. (2017). Mesoporous aluminum hydroxide synthesized by a single-source precursor-decomposition approach as a high-quantum-yield blue phosphor for UV-pumped white-light-emitting diodes. Adv. Mater. 29:8. doi: 10.1002/adma.201604284

Chen, G., Liu, H., Liang, H., Somesfalean, G., and Zhang, Z. (2008). Upconversion emission enhancement in $\mathrm{Yb}^{3+} / \mathrm{Er}^{3+}$-Codoped $\mathrm{Y}_{2} \mathrm{O}_{3}$ nanocrystals by tridoping with Li+ Ions. J. Phys. Chem. C 112, 12030-12036. doi: $10.1021 /$ jp804064g

Chen, G., Qiu, H., Prasad, P. N., and Chen, X. (2014). Upconversion nanoparticles: design, nanochemistry, and applications in theranostics. Chem. Rev. 114, 5161-5214. doi: 10.1021/cr400425h

Chen, G., Yang, C., and Prasad, P. N. (2013). Nanophotonics and nanochemistry: controlling the excitation dynamics for frequency up- and down-conversion in lanthanide-doped nanoparticles. Acc. Chem. Res. 46, 1474-1486. doi: $10.1021 /$ ar300270y

Chen, Q. S., Xie, X. J., Huang, B. L., Liang, L. L., Han, S. Y., Yi, Z. G., et al. (2017). Confining excitation energy in $\mathrm{Er}^{3+}$-sensitized upconversion nanocrystals through $\mathrm{Tm}^{3+}$-mediated transient energy trapping. Angew. Chem., Int. Ed. 56, 7605-7609. doi: 10.1002/anie.201703012

Cheng, Q., Sui, J., and Cai, W. (2012). Enhanced upconversion emission in Yb3+ and $\mathrm{Er} 3+$ codoped NaGdF4 nanocrystals by introducing $\mathrm{Li}+$ ions. Nanoscale 4, 779-784. doi: $10.1039 / \mathrm{cln} 11365 \mathrm{~h}$

Clarke, C., Liu, D., Wang, F., Liu, Y., Chen, C., Ton-That, C., et al. (2018). Large-scale dewetting assembly of gold nanoparticles for plasmonic enhanced upconversion nanoparticles. Nanoscale 10, 6270-6276. doi: 10.1039/C7NR08979A

Dong, H., Sun, L. D., and Yan, C. H. (2013). Basic understanding of the lanthanide related upconversion emissions. Nanoscale 5, 5703-5714. doi: $10.1039 / \mathrm{c} 3 \mathrm{nr} 34069 \mathrm{~d}$

Dong, H., Sun, L. D., and Yan, C. H. (2015). Energy transfer in lanthanide upconversion studies for extended optical applications. Chem. Soc. Rev. 44, 1608-1634. doi: $10.1039 / \mathrm{c} 4 \mathrm{cs} 00188 \mathrm{e}$

Du, P., Kim, E.-J., and Yu, J. S. (2018). Local symmetry distortion-induced enhancement of upconversion luminescence in $\mathrm{Gd}_{2} \mathrm{O}_{3}: \mathrm{Ho}^{3+} / \mathrm{Yb}^{+} / \mathrm{Zn} 2+$ nanoparticles for solid-state lighting and bioimaging. Curr. Appl. Phys. 18, 310-316. doi: 10.1016/j.cap.2018.01.004

Fan, Y., Liu, L., and Zhang, F. (2019). Exploiting lanthanide-doped upconversion nanoparticles with core/shell structures. Nano Today 25, 68-94. doi: 10.1016/j.nantod.2019.02.009

Fan, Y., Wang, P., Lu, Y., Wang, R., Zhou, L., Zheng, X., et al. (2018). Lifetimeengineered NIR-II nanoparticles unlock multiplexed in vivo imaging. Nat. Nanotechnol. 13, 941-946. doi: 10.1038/s41565-018-0221-0

Fischer, S., Mehlenbacher, R. D., Lay, A., Siefe, C., Alivisatos, A. P., and Dionne, J. A. (2019). Small alkaline-earth-based core/shell nanoparticles for efficient upconversion. Nano Lett. 19, 3878-3885. doi: 10.1021/acs.nanolett.9b01057

Han, S., Deng, R., Xie, X., and Liu, X. (2014). Enhancing luminescence in lanthanide-doped upconversion nanoparticles. Angew. Chem. Int. Ed. Engl. 53, 11702-11715. doi: 10.1002/anie.201403408

He, S., Johnson, N. J. J., Nguyen Huu, V. A., Cory, E., Huang, Y., Sah, R. L., et al. (2017). Simultaneous enhancement of photoluminescence, MRI relaxivity, and CT contrast by tuning the interfacial layer of lanthanide heteroepitaxial nanoparticles. Nano Lett. 17, 4873-4880. doi: 10.1021/acs.nanolett.7b01753
Huang, J., Hou, Y., Liu, C., Jing, L., Ma, T., Sun, X., et al. (2015). Chemical spacer design for engineering the relaxometric properties of coreshell structured rare earth nanoparticles. Chem. Mater. 27, 7918-7925. doi: 10.1021/acs.chemmater.5b02875

Huang, P., Zheng, W., Gong, Z., You, W., Wei, J., and Chen, X. (2019). Rare earth ion- and transition metal ion-doped inorganic luminescent nanocrystals: from fundamentals to biodetection. Materials Today Nano 5:100031. doi: 10.1016/j.mtnano.2019.100031

Johnson, N. J., He, S., Diao, S., Chan, E. M., Dai, H., and Almutairi, A. (2017). Direct evidence for coupled surface and concentration quenching dynamics in lanthanide-doped nanocrystals. J. Am. Chem. Soc. 139, 3275-3282. doi: $10.1021 /$ jacs.7b00223

Kar, A., and Patra, A. (2012). Impacts of core-shell structures on properties of lanthanide-based nanocrystals: crystal phase, lattice strain, downconversion, upconversion and energy transfer. Nanoscale 4, 3608-3619. doi: $10.1039 / \mathrm{c} 2 \mathrm{nr} 30389 \mathrm{~b}$

Lei, L., Chen, D., Huang, P., Xu, J., Zhang, R., and Wang, Y. (2013). Modifying the size and uniformity of upconversion $\mathrm{Yb} / \mathrm{Er}: \mathrm{NaGdF}_{4}$ nanocrystals through alkaline-earth doping. Nanoscale 5, 11298. doi: 10.1039/c3nr03497f

Li, X., Shen, D., Yang, J., Yao, C., Che, R., Zhang, F., et al. (2013). Successive layer-by-layer strategy for multi-shell epitaxial growth: shell thickness and doping position dependence in upconverting optical properties. Chem. Mater. 25, 106-112. doi: $10.1021 / \mathrm{cm} 3033498$

Li, Y., Zhang, P., Ning, H., Zeng, J., Hou, Y., Jing, L., et al. (2019). Emitting/sensitizing ions spatially separated lanthanide nanocrystals for visualizing tumors simultaneously through up- and downconversion near-infrared II luminescence in vivo. Small 15:e1905344. doi: 10.1002/smll.201905344

Liu, C., Gao, Z., Zeng, J., Hou, Y., Fang, F., Li, Y., et al. (2013). Magnetic/upconversion fluorescent $\mathrm{NaGdF}_{4}: \mathrm{Yb}$,Er nanoparticle-based dualmodal molecular probes for imaging tiny tumors in vivo. ACS Nano 7 , 7227-7240. doi: $10.1021 / \mathrm{nn} 4030898$

Liu, C., Hou, Y., and Gao, M. (2014). Are rare-earth nanoparticles suitable for in vivo applications? Adv. Mater. 26, 6922-6932. doi: 10.1002/adma.201305535

Liu, C., Qi, Y., Qiao, R., Hou, Y., Chan, K., Li, Z., et al. (2016). Detection of early primary colorectal cancer with upconversion luminescent NP-based molecular probes. Nanoscale 8, 12579-12587. doi: 10.1039/c5nr07858j

Liu, Y., Luo, W., Li, R., Liu, G., Antonio, M. R., and Chen, X. (2008). Optical Spectroscopy of $\mathrm{Eu}^{3+}$ Doped ZnO Nanocrystals. J. Phys. Chem. C 112, 686-694. doi: $10.1021 /$ jp077001z

Lu, M., Guo, J., Sun, S., Lu, P., Wu, J., Wang, Y., et al. (2020). Bright CsPbI3 perovskite quantum dot light-emitting diodes with top-emitting structure and a low efficiency roll-off realized by applying zirconium acetylacetonate surface modification. Nano Lett. 20, 2829-2836. doi: 10.1021/acs.nanolett.0c00545

Ma, C., Xu, X., Wang, F., Zhou, Z., Liu, D., Zhao, J., et al. (2017). Optimal sensitizer concentration in single upconversion nanocrystals. Nano Lett. 17, 2858-2864. doi: 10.1021/acs.nanolett.6b05331

Shannon, R. D., and Fischer, R. X. (2016). Empirical electronic polarizabilities of ions for the prediction and interpretation of refractive indices: oxides and oxysalts. Am. Mineral. 101, 2288-2300. doi: 10.2138/am-2016-5730

Shen, J., Zhao, L., and Han, G. (2013). Lanthanide-doped upconverting luminescent nanoparticle platforms for optical imaging-guided drug delivery and therapy. Adv. Drug Deliver. Rev 65, 744-755. doi: 10.1016/j.addr.2012.05.007

Stroyuk, O., Raevskaya, A., and Gaponik, N. (2018). Solar light harvesting with multinary metal chalcogenide nanocrystals. Chem. Soc. Rev. 47, 5354-5422. doi: $10.1039 / \mathrm{c} 8 \mathrm{cs} 00029 \mathrm{~h}$

Sun, Q. C., Mundoor, H., Ribot, J. C., Singh, V., Smalyukh, I. I., and Nagpal, P. (2014). Plasmon-enhanced energy transfer for improved upconversion of infrared radiation in doped-lanthanide nanocrystals. Nano Lett. 14, 101-106. doi: $10.1021 / \mathrm{nl} 403383 \mathrm{w}$

Tang, H., Xu, Y., and Cheng, X. (2020a). Growth and enhanced upconversion luminescence intensity of $\mathrm{Mg} 2+$ and $\mathrm{Cr} 3+$ co-doped beta- $\mathrm{NaYF}_{4}: \mathrm{Yb}^{3+} / \mathrm{Er}^{3+}$ microcrystals. J. Solid State Chem. 285:121229. doi: 10.1016/j.jssc.2020.121229

Tang, H., Zhou, H., and Cheng, X. (2020b). Effects of Ca2+ doping on upconversion luminescence intensity and crystal field asymmetry of beta- $\mathrm{NaYF}_{4}: \mathrm{Yb}^{3+} / \mathrm{Er}^{3+}$ microcrystals. J. Lumin. 221:117086. doi: 10.1016/j.jlumin.2020.117086 
Tang, J., Chen, L., Li, J., Wang, Z., Zhang, J., Zhang, L., et al. (2015). Selectively enhanced red upconversion luminescence and phase/size manipulation via $\mathrm{Fe}^{3+}$ doping in $\mathrm{NaYF}_{4}$ :Yb,Er nanocrystals. Nanoscale 7, 14752-14759. doi: 10.1039/c5nr04125b

Tu, D., Liu, Y., Zhu, H., Li, R., Liu, L., and Chen, X. (2013). Breakdown of crystallographic site symmetry in lanthanide-doped $\mathrm{NaYF}_{4}$ crystals. Angew. Chem. Int. Ed. Engl. 52, 1128-1133. doi: 10.1002/anie.201208218

Tu, L., Liu, X., Wu, F., and Zhang, H. (2015). Excitation energy migration dynamics in upconversion nanomaterials. Chem. Soc. Rev. 44, 1331-1345. doi: $10.1039 / \mathrm{c} 4 \mathrm{cs} 00168 \mathrm{k}$

Verma, P., Sarkar, D., Rajput, P., Singh, M. N., Sharma, R., and Giri, S. (2020). Synchrotron-based X-ray analysis: relating compressive lattice strain with the photoluminescence intensity of $\mathrm{Li}^{+}$-doped beta-NaYF $4: \mathrm{Yb}^{3+} / \mathrm{Ln}^{3+}\left(\mathrm{Ln}^{3+}=\right.$ $\mathrm{Ho}^{3+} / \mathrm{Er}^{3+} / \mathrm{Tm}^{3+}$ ) Upconversion Crystals. Crystal Growth Design 20, 468-478. doi: 10.1021/acs.cgd.9b01426

Vetrone, F., Naccache, R., Mahalingam, V., Morgan, C. G., and Capobianco, J. A. (2009). The active-core/active-shell approach: a strategy to enhance the upconversion luminescence in lanthanide-doped nanoparticles. Adv. Funct. Mater. 19, 2924-2929. doi: 10.1002/adfm.200900234

Walsh, B. M., Barnes, N. P., and Di Bartolo, B. (1998). Branching ratios, cross sections, and radiative lifetimes of rare earth ions in solids: application to $\mathrm{Tm}^{3+}$ and $\mathrm{Ho}^{3+}$ ions in $\mathrm{LiYF}_{4}$. J. Appl. Phys. 83, 2772-2787. doi: 10.1063/1.367037

Wang, F., Wang, J., and Liu, X. (2010). Direct evidence of a surface quenching effect on size-dependent luminescence of upconversion nanoparticles. Angew. Chem. Int. Ed. Engl. 49, 7456-7460. doi: 10.1002/anie.2010 03959

Wang, J., Wang, F., Wang, C., Liu, Z., and Liu, X. (2011). Single-band upconversion emission in lanthanide-doped $\mathrm{KMnF}_{3}$ nanocrystals. Angew. Chem. Int. Ed. 50, 10369-10372. doi: 10.1002/anie.201104192

Werts, M. H. V., Jukes, R. T. F., and Verhoeven, J. W. (2002). The emission spectrum and the radiative lifetime of $\mathrm{Eu}^{3+}$ in luminescent lanthanide complexes. Phys. Chem. Chem. Phys. 4, 1542-1548. doi: 10.1039/b1 07770h
Xu, J., Gulzar, A., Yang, P., Bi, H., Yang, D., Gai, S., et al. (2019). Recent advances in near-infrared emitting lanthanide-doped nanoconstructs: mechanism, design and application for bioimaging. Coordin. Chem. Rev. 381, 104-134. doi: 10.1016/j.ccr.2018.11.014

Yi, G. S., and Chow, G. M. (2007). Water-soluble $\mathrm{NaYF}_{4}: \mathrm{Yb}, \operatorname{Er}(\mathrm{Tm}) / \mathrm{NaYF}_{4} /$ polymer core/shell/shell nanoparticles with significant enhancement of upconversion fluorescence. Chem. Mater. 19, 341-343. doi: 10.1021/cm062447y

Zeng, S., Yi, Z., Lu, W., Qian, C., Wang, H., Rao, L., et al. (2014). Simultaneous realization of phase/size manipulation, upconversion luminescence enhancement, and blood vessel imaging in multifunctional nanoprobes through transition metal $\mathrm{Mn}^{2+}$ doping. Adv. Funct. Mater. 24, 4051-4059. doi: 10.1002/adfm.201304270

Zhang, Y., Chen, B., Xu, S., Li, X., Zhang, J., Sun, J., et al. (2018). A universal approach for calculating the Judd-Ofelt parameters of $\mathrm{RE}^{3+}$ in powdered phosphors and its application for the beta- $\mathrm{NaYF}_{4}: \mathrm{Er}^{3+} / \mathrm{Yb}^{3+}$ phosphor derived from auto-combustion-assisted fluoridation. Phys. Chem. Chem. Phys. 20, 15876-15883. doi: 10.1039/c8cp02317d

Zhou, J., Liu, Z., and Li, F. Y. (2012). Upconversion nanophosphors for smallanimal imaging. Chem. Soc. Rev. 41, 1323-1349. doi: 10.1039/clcs15187h

Conflict of Interest: The authors declare that the research was conducted in the absence of any commercial or financial relationships that could be construed as a potential conflict of interest.

Copyright (C) $2020 \mathrm{Li}$, Liu, Zhang, Huang, Ning, Xiao, Hou, Jing and Gao. This is an open-access article distributed under the terms of the Creative Commons Attribution License (CC BY). The use, distribution or reproduction in other forums is permitted, provided the original author(s) and the copyright owner(s) are credited and that the original publication in this journal is cited, in accordance with accepted academic practice. No use, distribution or reproduction is permitted which does not comply with these terms. 